\title{
Fibro-adipose vascular anomaly (FAVA): three case reports with an emphasis on the mammalian target of rapamycin (mTOR) pathway
}

Yumiko Hori ${ }^{1}$, Katsutoshi Hirose ${ }^{2}$, Noriko Aramaki-Hattori ${ }^{3}$, Sachi Suzuki ${ }^{4}$, Robert Nakayama ${ }^{5}$, Masanori Inoue ${ }^{6}$, Takahiro Matsui ${ }^{1}$, Masaharu Kohara', Satoru Toyosawa ${ }^{2}$ and Eiichi Morii ${ }^{1{ }^{*}}$

\begin{abstract}
Background: Fibro-adipose vascular anomaly (FAVA) is a new entity of vascular anomalies with somatic and mosaic gain-of-function mutations of the phosphatidylinositol-4, 5-bisphosphate 3-kinase catalytic subunit alpha (PIK3CA). PIK3CA mutation excessively activates mammalian target of rapamycin (mTOR) pathway, which promotes angiogenesis and lymphangiogenesis. Histologically, FAVA is composed of intramuscular fibrous and adipose tissues with venous malformation (VM). Although sirolimus known as a mTOR inhibitor has good response to FAVA, expression pattern of the mTOR pathway was still unclear. Herein, we immunohistochemically investigated three novel FAVA patients with an emphasis on the mTOR pathway (p-S6K1, p-4EBP1 and p-AKT).

Case presentation: Case 1: A 10-year-old female had complained of pain in the left thigh since she was 6-year-old. Under the clinical diagnosis of VM, she underwent surgical resection for the lesion. Case 2: A 29-year-old female patient had complained of discomfort and mild pain in the left shoulder since she was 18-year-old. After childbirth, she had severe ongoing pain and contracture of the shoulder. Under clinical diagnosis of VM, surgical resection was performed. Case 3: A 53-year-old female had complained of pain and knee restriction after surgical treatment of a knee tumor at the age of 31. Under the clinical diagnosis of atypical lipomatous tumor or high grade liposarcoma, surgical resection was performed. Histologically, all three patients presented with characteristic features of fibrous and adipose tissues with abnormal vessels within the skeletal muscle, leading to diagnosis of FAVA. Although VM has been reported as an important finding in FAVA, immunohistological findings demonstrated that abnormal vessels comprised complex of VM and lymphatic malformation (LM) in all cases. Furthermore, besides vascular malformation, abnormal fibrous and adipose tissues of FAVA expressed mTOR pathway components.

Conclusions: We presented three new cases of FAVA. Histological and immunohistochemical analyses revealed that VM and LM complex was an important finding in FAVA, and that the mTOR pathway components were expressed in abnormal fibrous tissue, adipose tissue and vascular malformation. These findings suggested that FAVA might be a mesenchymal malformation caused by PI3K/AKT/mTOR pathway.
\end{abstract}

Keywords: Fibro-adipose vascular anomaly (FAVA), PIK3CA, mTOR, Vascular anomaly

\footnotetext{
* Correspondence: morii@molpath.med.osaka-u.ac.jp

'Department of Pathology, Osaka University Graduate School of Medicine,

2-2 Yamada-oka, Suita, Osaka 565-0871, Japan

Full list of author information is available at the end of the article
}

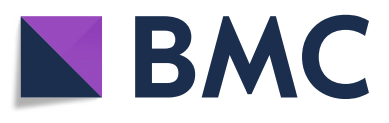

(c) The Author(s). 2020 Open Access This article is licensed under a Creative Commons Attribution 4.0 International License, which permits use, sharing, adaptation, distribution and reproduction in any medium or format, as long as you give appropriate credit to the original author(s) and the source, provide a link to the Creative Commons licence, and indicate if changes were made. The images or other third party material in this article are included in the article's Creative Commons licence, unless indicated otherwise in a credit line to the material. If material is not included in the article's Creative Commons licence and your intended use is not permitted by statutory regulation or exceeds the permitted use, you will need to obtain permission directly from the copyright holder. To view a copy of this licence, visit http://creativecommons.org/licenses/by/4.0/. The Creative Commons Public Domain Dedication waiver (http://creativecommons.org/publicdomain/zero/1.0/) applies to the data made available in this article, unless otherwise stated in a credit line to the data. 


\section{Background}

Fibro-adipose vascular anomaly (FAVA) is a new entity of vascular anomalies, and has not been included in the International Society for the Study of Vascular Anomalies (ISSVA) classification [1]. FAVA is an extremely rare and a recently described vascular anomaly with approximate 20 cases in the literatures [1-5]. It is often present during young age, and occurs in the muscle of the lower extremities (about 90\%) followed by the upper extremities and trunk. The common presenting symptoms are pain (100\%), functional restriction (81\%) and swelling (62\%) [2]. FAVA affects females more frequently than males in a ratio of 3:1 [3, 4]. Histologically, FAVA is a complex mesenchymal malformation characterized by venous malformation (VM) surrounded by focal or diffuse fibro-adipose tissue within the skeletal muscle [1]. However, the abnormal lymphatic vessels accompanying VM were present in a few cases [1, 4]. Although VM was an important finding in FAVA, there was some room for discussion of the type of vascular malformation in FAVA.

Recent study identified that somatic and mosaic gainof-function mutations of the phosphatidylinositol-4,5bisphosphate 3-kinase Catalytic Subunit Alpha (PIK3CA) gene were found in FAVA, and FAVA belongs to the spectrum of PIK3CA-related overgrowth syndromes (PROS) [5-7]. PIK3CA encodes the 110-kD catalytic $\alpha-$ subunit of PI3K, which is the key lipid kinase that controls signaling pathways involved in cell proliferation, motility, survival and metabolism [8]. Activation of PI3K via different receptors results in phosphorylation of $\mathrm{AKT}$, and $\mathrm{p}-\mathrm{AKT}$ phosphorylates mammalian target of rapamycin (mTOR). Furthermore, phosphorylated form of mTOR also phosphorylates the downstream target of the ribosomal protein S6 kinase 1 (S6K1) and eukaryotic translation initiation factor 4E-binding protein 1 (4EBP1), which have a stimulatory function of increase in protein synthesis and cell growth in angiogenesis and lymphangiogenesis [7, 9-12]. In vitro study demonstrated that PIK3CA mutation excessively promoted activation of mTOR pathway [7, 13]. Moreover, sirolimus known as a mTOR inhibitor has an antiproliferative effect on various vascular anomalies including FAVA [3, 14, 15]. Considering these findings, activated PI3K/AKT/ mTOR signaling pathway plays a key role in pathogenesis of vascular anomaly in FAVA. In this study, we reported three novel cases of FAVA, in which the immunohistochemical profile of blood vessel, lymphatic vessel and mTOR pathway was investigated.

\section{Case presentation}

\section{Clinical findings}

Case 1

A 10-year-old female had complained of pain in the left thigh since she was 6-year-old. She had no significant prior medical or surgical history. Both axial T2-weighted Magnetic resonance imaging (MRI) and coronal fatsaturated enhanced T1-weighted MRI revealed heterogenous hyperintense within the skeletal muscle (Fig. 1a, b). The clinical diagnosis was VM. Restriction of the knee joint gradually appeared. Although sclerotherapy was attempted, no benefit was obtained. Additional ultrasonographic examination imaging showed an illdefined hyperechoic intramuscular solid mass. Needle biopsy was performed, and VM was diagnosed. Then, surgical resection was performed.

\section{Case 2}

A 29-year-old female patient had complained of discomfort and mild pain in the left shoulder since she was 18year-old. After childbirth, she had severe ongoing pain and contracture of the shoulder. She had no significant prior medical or surgical history. Axial fat-saturated T2weighted MRI revealed high signal intensity and sagittal T1-weighted MRI revealed low signal intensity within the muscle of the shoulder. (Fig. 1c, d). Under clinical diagnosis of VM, the lesion was resected.

\section{Case 3}

A 53-year-old female had complained of pain and knee restriction after surgical treatment of a knee tumor at the age of 31. The details of surgical treatment were unclear. Axial T1-weighted MRI revealed low signal with fat component and sagittal fat-saturated T2-weighted MRI revealed high signal intensity (Fig. 1e, f). Under the clinical diagnosis of atypical lipomatous tumor or high grade liposarcoma, needle biopsy was performed, and the diagnosis of angiomatosis was made. Then, surgical resection was performed. After the resection, knee restriction disappeared.

\section{Histological findings}

All three lesions were included in skeletal muscle (Fig. 2a). The most common findings were abnormal vessels and dispersed skeletal muscle islands surrounded by extensive fibrous and adipose tissue (Fig. 2b, black box in Fig. 2a). Moreover, the vascular clusters consisted of thin-walled back-to-back blood-filled sacs were observed (Fig. 2c, dot box in Fig. 2a). These clusters were frequently surrounded by lymphocytic aggregates (Fig. 2b, c). Although VM has been characterized as an important finding in FAVA, the abnormal vessels comprised complex of VM and lymphatic malformation (LM) in various proportions among our three cases (Fig. 2d). In case 1, LM accounted for a substantial fraction of abnormal vessels. VM component is large and irregular malformed vessels with muscularized walls. LM component is malformed microcysts lined by round endothelial cells. The other findings were organized thrombi within abnormal veins in two cases. Despite previous 

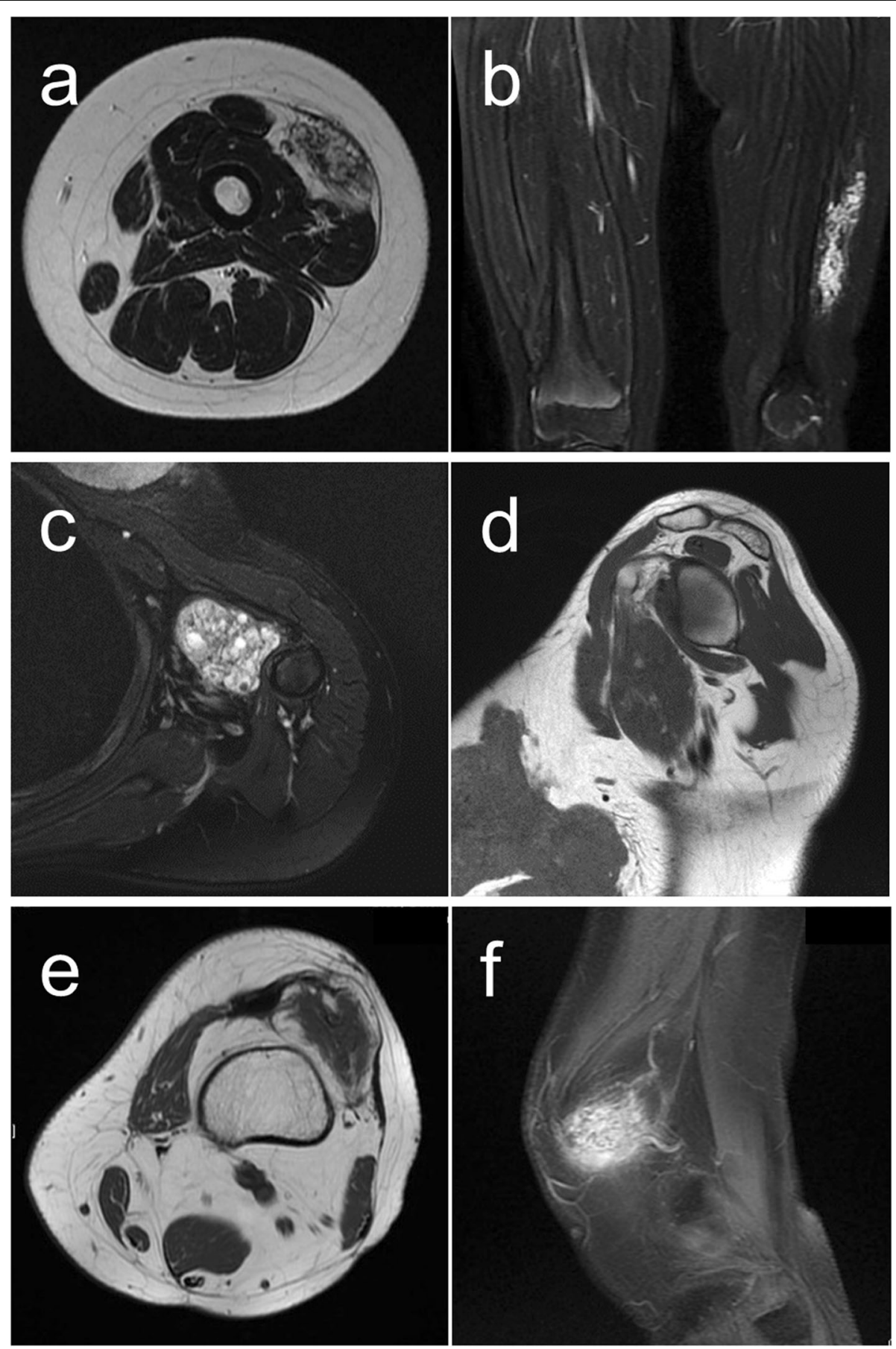

Fig. 1 Magnetic resonance imaging (MRI). Axial T2-weighted MRI (a) and coronal fat-saturated enhanced T1-weighted MRI (b) of case 1. Axial fat-saturated T2-weighted MRI (c) and sagittal T1-weighted MRI (d) of case 2. Axial T1-weighted MRI (e) and sagittal fat-saturated T2-weighted MRI (f) of case 3

reports, no nerve containing enlarged venous vessels surrounded by dense fibrous tissue were seen in our cases [1].

\section{Immunohistochemistry}

First, we performed CD31 (clone JC70A, 1:200, Dako), CD34 (clone QBEnd10, 1:200, Dako), D2-40 (clone dp36,
1:100, Dako) and PROX1 (ab199359, 1:500; Abcam, Cambridge, U.K.) immunostaining to provide additional evidence of VM and LM in FAVA. In abnormal veins, CD31 and CD34 were positive and D2-40 and PROX1 were negative in all three cases (Fig. 2e-h, V; abnormal veins). In contrast to abnormal veins' staining, abnormal 

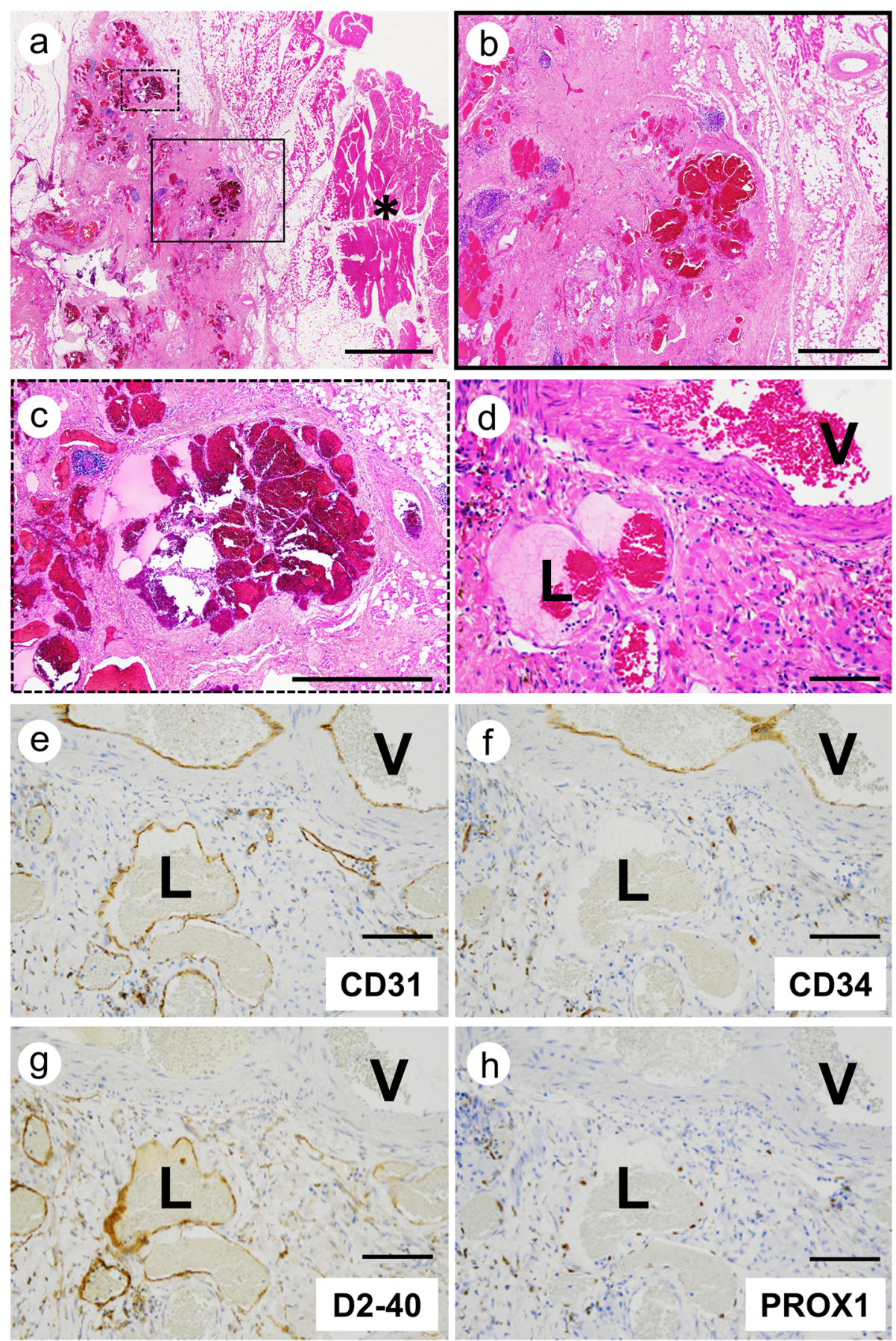

Fig. 2 Histology and immunohistochemical analysis of vascular markers. Representative H\&E staining of FAVA (a; loupe image, b; higher magnification of black box in a, $\mathbf{c}$; higher magnification of dot box in a). Asterisk $\left(^{*}\right)$ indicated skeletal muscle surrounding FAVA lesion. Serial sections stained for H\&E (d), CD31 (e), CD34 (f), D2-40 (g) and PROX1 (h). Abnormal veins (V) were positive for CD31 and CD34. Abnormal lymphatic vessels (L) were positive for CD31, D2-40 and PROX1. Scale bars: $\mathbf{a}=5000 \mu \mathrm{m} ; \mathbf{b}, \mathbf{c}=1000 \mu \mathrm{m} ; \mathbf{d}-\mathbf{h}=100 \mu \mathrm{m}$

lymphatic vessels were positive for CD31, D2-40 and PROX1, and negative for CD34 (Fig. 2e-h, L; abnormal lymphatic vessels).

Next, we analyzed the expression of mTOR pathway components, p-S6K1 (\#9204, 1:100; Cell Signaling
Technology, Danvers, MA, USA), p-4EBP1 (\#2855, 1: 500; Cell Signaling Technology) and p-AKT (\#4060, 1: 100; Cell Signaling Technology). Normal connective tissues surrounding FAVA lesions served as a control. Control normal tissues were mainly composed of 
skeletal muscle and normal vessels, because FAVA arises within skeletal muscle (Fig. 2a, asterisk). In our three cases, almost all abnormal vessels strongly expressed pS6K1 (Fig. 3a, b) and the fibro-adipose tissue also expressed that (Fig. 3e, f, i, j). In addition, p-4EBP1 expression was detected in these FAVA components in all cases (Fig. 3c, g, k). The p-AKT expression was detected in abnormal vessels and fibrous tissue in all cases, besides sporadic p-AKT expression was detected in adipose tissue in two cases (Fig. 3d, h, l). On the other hand, p-S6K1 showed sporadic expression in skeletal muscle and normal vessels, whereas $\mathrm{p}-4 \mathrm{EBP} 1$ and $\mathrm{p}$ AKT showed no expression in these tissues. (Fig. 3m-p). The summarized immunohistochemical results of all cases were shown in Table 1.

\section{Discussion}

In this study, we described three cases of previously unreported immunohistochemical characteristics of FAVA. Histological and immunohistochemical analyses revealed that lymphatic-venous malformation (LVM) was an important finding in FAVA, and the mTOR signaling pathway was expressed in various FAVA components.
Identification of vascular type was conducted using CD34 as markers for blood vessels, as well as D2-40 and PROX1 for lymphatic vessels. Histological and immunohistological findings demonstrated presence of complex of abnormal veins and lymphatic vessels in all three cases (Fig. 2d-h). The proportion of abnormal veins and lymphatic vessels was varied among our cases. There is a possibility that vascular malformation composing only VM in previous cases may include LM component [1-5]. LVM is combined vascular malformation $(\mathrm{VM}+\mathrm{LM})$. ISSVA defines "combined vascular malformation" as two or more vascular malformations found in one lesion. Thus, in FAVA, vascular malformation component may be LVM rather than VM.

Immunohistochemistry demonstrated that abnormal vessels of all our cases expressed the p-AKT and mTOR effector, p-S6K1 and p-4EBP1 (Fig. 3a-d and Table 1). Interestingly, abnormal fibrous tissue and adipose tissue also expressed these mTOR pathway components (Fig. 3e-l and Table 1). Previous studies demonstrated that $\mathrm{p}-\mathrm{S} 6 \mathrm{~K} 1$ was not detected in non-neoplastic fibrous tissue and adipose tissue $[16,17]$, besides p-S6K1 showed sporadic expression in normal vessels $[18,19]$. Furthermore, both p-AKT and p-

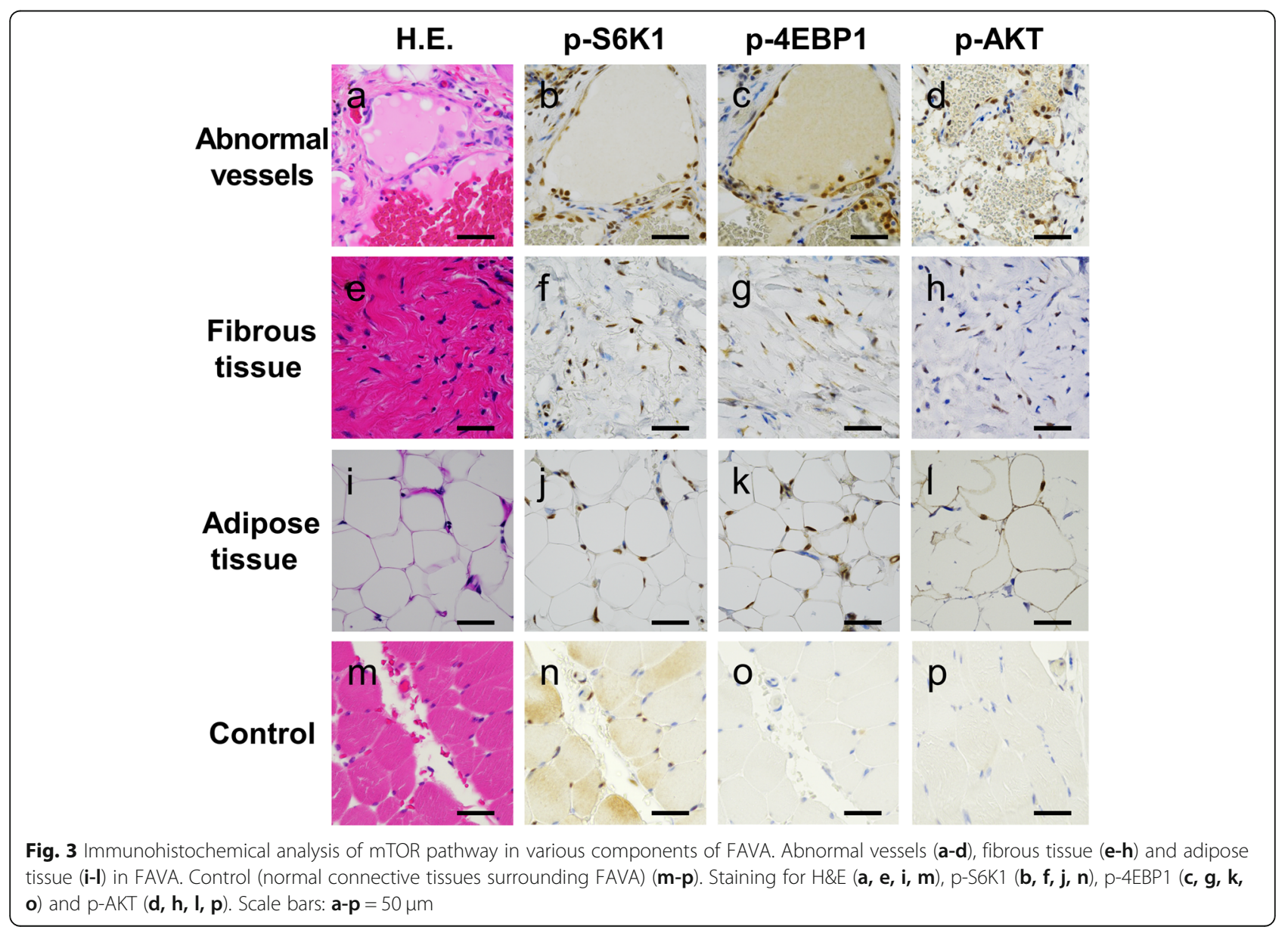


Table 1 Immunohistochemical expression of PI3K/AKT/mTOR pathway in various components

\begin{tabular}{lllll}
\hline & & p-S6K1 & p-4EBP1 & p-AKT \\
\hline Case 1. & Abnormal vessels & + & + & + \\
& Fibrous Tissue & + & + & + \\
& Adipose Tissue & + & + & + \\
Case 2. & Abnormal vessels & + & + & + \\
& Fibrous Tissue & + & + & + \\
& Adipose Tissue & + & + & + \\
Case 3. & Abnormal vessels & + & + & + \\
& Fibrous Tissue & + & + & + \\
& Adipose Tissue & + & + & - \\
Control & Skeletal muscle, Vessels & + & - & - \\
\hline
\end{tabular}

Staining intensity (-; no expression / +; positive)

4EBP1 were not detected in non-neoplastic vessels, fibrous tissue and adipose tissue [16, 17, 19-21]. Thus, PI3K/AKT/ mTOR pathway in mesenchymal malformation of FAVA is activated compared to that in normal tissue. These observations were consistent with the previous reports that PIK3CA mutations have been detected in adipocytes in PROS [22], subcultured fibroblasts in FAVA [6, 7] and lymphatic endothelial cells in LM [7, 23]. Moreover, PIK3CA mutation in fibroblast cell line excessively promoted PI3K/AKT/mTOR signaling and phosphorylation of its downstream $[6,24]$. Hence, the phosphorylation of S6K1 and 4EBP1 may promote not only angiogenesis and lymphangiogenesis, but also fibrogenesis and adipogenesis in FAVA.

Jonathan E et al. (2017) presented two cases of FAVA with mTOR inhibitor sirolimus treatment [3]. Before that, there were no specific treatment for FAVA because of the overall low incidence. A few patients underwent surgical excision, sclerotherapy and cryablation [2]. Sirolimus has been shown to improve various vascular malformations by suppressing activation of mTOR, S6K1 and 4EBP1 [25]. In fact, sirolimus was rapidly effective for FAVA patients [3]. However, how sirolimus affected FAVA remains unclear. Our results suggested that sirolimus suppressed phosphorylation of mTOR pathway in not only abnormal vessels but also fibro-adipose tissue in FAVA.

\section{Conclusions}

FAVA is a rare vascular malformation with PIK3CA mutation. We presented three new cases of FAVA. Histological and immunohistochemical analyses revealed that LVM was an important finding in FAVA, and that the mTOR pathway components were expressed in abnormal fibrous tissue, adipose tissue and vascular malformation.

\section{Abbreviations}

4EBP1: Eukaryotic translation initiation factor 4E-binding protein 1; FAVA: Fibro-adipose vascular anomaly; LM: Lymphatic malformation; LVM: Lymphatic venous malformation; mTOR: Mammalian target of rapamycin;

PIK3CA: Phosphatidylinositol-4, 5-bisphosphate 3-kinase catalytic subunit alpha; PROS: The spectrum of PIK3CA-related overgrowth syndromes; S6K1: Ribosomal protein S6 kinase 1; VM: Venous malformation

\section{Acknowledgements}

Not applicable.

\section{Authors' contributions}

All authors contributed to this work. $\mathrm{YH}$ and $\mathrm{KH}$ participated in the concept of this study and wrote the manuscript. These two authors contributed equally to this work. YH, KH, TM, MK and ST performed the experiments and assembled data. $\mathrm{YH}, \mathrm{KH}$ and EM were responsible for the concept of this study and critically revised the manuscript for intellectual content. NA-H, SS, $\mathrm{RN}$ and $\mathrm{Ml}$ cared for the patient. All authors reviewed and approved the manuscript for submission.

\section{Funding}

This work was supported by JSPS KAKENHI (18 K15079 and A19H034520).

\section{Availability of data and materials}

The surgical materials and the datasets analyzed during the current study are available from the corresponding author on reasonable request.

Ethics approval and consent to participate

This study was approved by the Ethical Review Board of the Graduate School of Medicine, Osaka University (No. 17214) and was performed in accordance with the Committee guidelines and regulations.

\section{Consent for publication}

Written informed consent for publication of their clinical details and clinical images was obtained from the patients. A copy of the consent form is available for review by the Editor of this journal.

\section{Competing interests}

The authors declare no conflicts of interest.

\section{Author details}

${ }^{1}$ Department of Pathology, Osaka University Graduate School of Medicine, 2-2 Yamada-oka, Suita, Osaka 565-0871, Japan. Department of Oral Pathology, Osaka University Graduate School of Dentistry, 1-8 Yamada-oka, Suita, Osaka 565-0871, Japan. ${ }^{3}$ Department of Plastic and Reconstructive Surgery, Keio University School of Medicine, 35 Shinanomachi, Shinjuku-ku, Tokyo 160-8582, Japan. ${ }^{4}$ Department of Plastic and Reconstructive Surgery, Japanese Red Cross Shizuoka Hospital, 8-2 Outemachi, Aoi-ku, Shizuoka-shi, Shizuoka 420-0853, Japan. ${ }^{5}$ Department of Orthopaedic Surgery, Keio University School of Medicine, 35 Shinanomachi, Shinjuku-ku, Tokyo 160-8582, Japan. ${ }^{6}$ Department of Diagnostic Radiology, Keio University School of Medicine, 35 Shinanomachi, Shinjuku-ku, Tokyo 160-8582, Japan.

Received: 31 October 2019 Accepted: 14 July 2020

Published online: 25 July 2020

\section{References}

1. Alomari Al, Spencer SA, Arnold RW, et al. Fibro-adipose vascular anomaly: clinical-radiologic-pathologic features of a newly delineated disorder of the extremity. J Pediatr Orthop. 2014;34:109-17.

2. Shaikh R, Alomari Al, Kerr CL, Miller P, Spencer SA. Cryoablation in fibroadipose vascular anomaly (FAVA): a minimally invasive treatment option. Pediatr Radiol. 2016;46:1179-86.

3. Erickson J, McAuliffe W, Blennerhassett L, Halbert A. Fibroadipose vascular anomaly treated with sirolimus: successful outcome in two patients. Pediatr Dermatol. 2017;34:e317-20.

4. Fernandez-Pineda I, Marcilla D, Downey-Carmona FJ, Roldan S, OrtegaLaureano L, Bernabeu-Wittel J. Lower extremity fibro-adipose vascular anomaly (FAVA): a new case of a newly delineated disorder. Ann Vasc Dis. 2014;7:316-9. 
5. Youssefian L, Vahidnezhad H, Baghdadi T, Ghaznavi A, Li Q, Tabrizi M, et al. Fibroadipose hyperplasia versus Proteus syndrome: segmental overgrowth with a mosaic mutation in the PIK3CA gene. J Invest Dermatol. 2015;135: 1450-3.

6. Lindhurst MJ, Parker VE, Payne F, et al. Mosaic overgrowth with fibroadipose hyperplasia is caused by somatic activating mutations in PIK3CA. Nat Genet. 2012:44:928-33.

7. Luks VL, Kamitaki N, Vivero MP, et al. Lymphatic and other vascular malformative/overgrowth disorders are caused by somatic mutations in PIK3CA. J Pediatr. 2016;166:1048-54 e1-5.

8. Vanhaesebroeck B, Stephens L, Hawkins P. PI3K signalling: the path to discovery and understanding. Nat Rev Mol Cell Biol. 2012;13:195-203.

9. von Manteuffel SR, Dennis PB, Pullen N, Gingras AC, Sonenberg N, Thomas $G$. The insulin-induced signalling pathway leading to $S 6$ and initiation factor 4Ebinding protein 1 phosphorylation bifurcates at a rapamycin-sensitive pointimmediately upstream of p70s6k. Mol Cell Biol. 1997;17:5426-36.

10. Whalen SG, Gingras AC, Amankwa L, et al. Phosphorylation of elF-4E on serine 209 by protein kinase $C$ is inhibited by the translational repressors, 4E-binding proteins. J Biol Chem. 1996;271:11831-7.

11. Dennis PB, Pullen N, Kozma SC, Thomas G. The principal rapamycin-sensitive p70 (s6k) phosphorylation sites, T-229 and T-389, are differentially regulated by rapamycin-insensitive kinase kinases. Mol Cell Biol. 1996;16:6242-51.

12. Gingras AC, Raught $B$, Sonenberg N. Regulation of translation initiation by FRAP/mTOR. Genes Dev. 2001;15:807-26.

13. Gao X, Zhang Y, Arrazola P, Hino O, Kobayashi T, Yeung RS, et al. Tsc tumour suppressor proteins antagonize amino-acid-TOR signalling. Nat Cell Biol. 2002;4:699-704.

14. Adams DM, Trenor CC 3rd, Hammill AM, et al. Efficacy and safety of Sirolimus in the treatment of complicated vascular anomalies. Pediatrics. 2016;137:e20153257.

15. Maruani A, Boccara O, Bessis D, et al. Treatment of voluminous and complicated superficial slow-flow vascular malformations with sirolimus (PERFORMUS): protocol for a multicenter phase 2 trial with a randomized observational-phase design. Trials. 2018;19:340

16. No JH, Jeon YT, Park IA, et al. Activation of mTOR signaling pathway associated with adverse prognostic factors of epithelial ovarian cancer. Gynecol Oncol. 2011:121:8-12.

17. Ma BL, Shan MH, Sun G, Ren GH, Dong C, Yao X, et al. Immunohistochemical analysis of phosphorylated mammalian target of rapamycin and its downstream signaling components in invasive breast cancer. Mol Med Rep. 2015;12:5246-54.

18. Patel V, Marsh CA, Dorsam RT, et al. Decreased Lymphangiogenesis and lymph node metastasis by mTOR inhibition in head and neck cancer. Cancer Res. 2011;71:7103-12.

19. Hori Y, Ozeki M, Hirose $K$, et al. Analysis of mTOR pathway expression in lymphatic malformation and related diseases. Pathol Int. 2020;70:323-9.

20. Gutierrez A, Snyder EL, Marino-Enriquez A, et al. Aberrant AKT activation drives well-differentiated liposarcoma. Proc Natl Acad Sci U S A. 2011;108: 16386-91.

21. Faried LS, Faried A, Kanuma T, et al. Expression of an activated mammalian target of rapamycin in adenocarcinoma of the cervix: a potential biomarker and molecular target therapy. Mol Carcinog. 2008;47:446-57.

22. Kurek KC, Luks VL, Ayturk UM, et al. Somatic mosaic activating mutations in PIK3CA cause CLOVES syndrome. Am J Hum Genet. 2012;90:1108-15.

23. Boscolo E, Coma S, Luks VL, Greene AK, Klagsbrun M, Warman ML, et al. AKT hyper-phosphorylation associated with PI3K mutations in lymphatic endothelial cells from a patient with lymphatic malformation. Angiogenesis. 2015;18:151-62.

24. Loconte DC, Grossi V, Bozzao C, et al. Molecular and functional characterization of three different postzygotic mutations in PIK3CA-related overgrowth Spectrum (PROS) patients: effects on PI3K/AKT/mTOR signaling and sensitivity to PIK3 inhibitors. PLoS One. 2015;10:e0123092.

25. Kerjaschki D. How to control lymphangiogenesis: a novel role for rapamycin. Kidney Int. 2007;71:717-9.

\section{Publisher's Note}

Springer Nature remains neutral with regard to jurisdictional claims in published maps and institutional affiliations.

\section{Ready to submit your research? Choose BMC and benefit from}

- fast, convenient online submission

- thorough peer review by experienced researchers in your field

- rapid publication on acceptance

- support for research data, including large and complex data types

- gold Open Access which fosters wider collaboration and increased citations

- maximum visibility for your research: over $100 \mathrm{M}$ website views per year

At $\mathrm{BMC}$, research is always in progress.

Learn more biomedcentral.com/submissions 